\title{
Potential of culture filtrate from Trichoderma spp. as biofungicide to Colletotrichum gloeosporioides causing anthracnose disease in chili
}

\author{
NURBAILIS $^{1, \boldsymbol{v}}$, AKMAL DJAMAAN ${ }^{2}$, HALIATUR RAHMA ${ }^{1}$, YENNY LISWARNI $^{1}$ \\ ${ }^{1}$ Department of Plant Protection, Faculty of Agriculture, Universitas Andalas. Jl. Lingkar Unand, Limau Manis, Padang 25163, West Sumatra, Indonesia. \\ Tel.: +62-751-72701, Fax.: +62-751-72702, •email: nurbailis@agr.unand.ac.id \\ ${ }^{2}$ Faculty of Pharmacy, Universitas Andalas. Jl. Lingkar Unand, Limau Manis, Padang 25163, West Sumatra, Indonesia
}

Manuscript received: 6 August 2019. Revision accepted: 10 September 2019.

\begin{abstract}
Nurbailis, Djamaan A, Rahma H, Liswarni Y. 2019. Potential of culture filtrate from Trichoderma spp. as biofungicide to Colletotrichum gloeosporioides causing anthracnose disease in chili. Biodiversitas 20: 2915-2920. Trichoderma spp. have the potential to be used for controlling the airborne pathogenic fungi such as $C$. gloeosporioides. The purpose of this study was to evaluate the antifungal activity of the culture filtrate of five isolates of Trichoderma spp. (T. harzianum, T. viride, T. koningii, Trichoderma PP2, Trichoderma PP3) against C. gloeosporoides causing anthracnose disease in chili. Culture filtrate of Trichoderma spp. was produced from single culture and dual culture techniques. The design was a Completely Randomized Design with six treatments and four replications. The treatments were culture filtrate from T. harzianum, T. viride, T. koningii, Trichoderma PP2, Trichoderma PP3, and negative control (without culture filtrate from Trichoderma spp.). Parameters observed were: the diameter of the colony, colony coverage, conidial germination, and conidial density. The results of this research showed all the culture filtrate from Trichoderma spp. produced by single and dual culture techniques can inhibit the growth of $C$. gloeosporioides. The culture filtrate from Trichoderma PP2 and $T$. koningii were the most potential in inhibiting the growth, conidial density, and conidial germination of $C$. gloeosporioides.
\end{abstract}

Keywords: Biofungicide, Colletotrichum gloeosporioides, culture filtrate, Trichoderma

\section{INTRODUCTION}

Colletotrichum gloeosporioides is one of the fungi that cause anthracnose disease in chili. This pathogen infects the mature and immature fruit of chili, causing high loss of production (Roberts et al. 2008; Robert et al. 2015; Diao et al. 2017). In general, the control of anthracnose disease is carried out by the extensive use of fungicides which have a negative impact on the environment and consumers (Sharma and Kulshrestha 2015) Therefore; it is necessary to find alternative controls which are environmentally friendly by utilizing the antagonistic fungi such as Trichoderma spp. as biological control agents.

Trichoderma spp. are free-living fungi, antagonistic, nonvirulent, plant symbionts, as well as hyperparasite against plant pathogenic fungi (Harman et al. 2004). They are commonly found in all climatic zones with habitats that dispersed in various types of soil and agricultural land. The most typical habitats of these fungi include soil and rotting wood (Samuel 2006; Druzhinina et al. 2006). Trichoderma has several mechanisms in inhibiting the growth of plant pathogens which are: competition of space and nutrients, parasitic to the plant pathogens and antibiosis by producing secondary metabolites as antimicrobial (Howell 2003; Vinale et al. 2008). Trichoderma spp. induces pathogen inhibition by secreting secondary metabolites. Different Trichoderma species secrete different substances, including isonitrile, diketopiperazines, sesquiterpenes, stemids, polyketides, alkylpyrones, and peptaibols (Wu et al. 2017).
Utilization of Trichoderma spp. to control pathogens that attack parts of the plant surface such as leaves and fruit have not been widely reported. Trichoderma has the potential to be developed for controlling this disease by utilizing secondary metabolites that are produced as antifungal and antibacterial compounds (Dubey et al. 2011; Leelavathy et al. 2014). Secondary metabolites produced by Trichoderma are chemically diverse, and their production varies between species and between isolates of the same species (Vinale et al. 2009). The vast structural and functional diversity of Trichoderma metabolites necessitates the continuous search for new metabolites. The generated knowledge may be necessary for the selection of new biocontrol agents, or the compounds themselves may be used as bioactive compounds in pesticide and antibiotic applications.(Mutawila et al. 2016).

Antibiosis is a mechanism of antagonistic fungi in inhibiting the growth of pathogens with antagonistic chemical products released into their environment, which include antibiotic components and extracellular enzyme systems that damage pathogens (Harman, et al. 2004; Woo, et al. 2006; Dubey et al. 2011; Leelavathy et al. 2014; Daniel et al. 2014). T. harzianum T22 and T39 strains produce secondary metabolites in the form of antibiotics that can suppress many plant pathogenic fungi such as Leptosphaeria muculans, Phytophthora cinnamomi, and Botrytis cinerea (Vinale et al. 2006).

Kumar et al. (2014) reported that secondary metabolites from T. harzianum (Th. Azad) and T. viride (01PP) 
produced with dual culture with various soil-borne pathogenic fungi showed that the metabolites produced were more effective in suppressing the growth of $F$. oxysporum growth. f.sp. lenti, Rhizoctonia solani, and Sclerotinia rolfsii. The higher the concentration of secondary metabolites, the more depressed pathogen growth.

Nurbailis et al. (2006) reported that $T$. viride and $T$. koningii, indigenous isolates from banana rhizosphere were able to inhibit the growth of $F$. oxysporum f.sp. cubense with an antibiosis, hyperparasite and competition mechanism. Nurbailis et al. (2014) also reported that Trichoderma PP2 and PP3 isolates originating from chili rhizosphere were effective in inhibiting the growth of $C$. gloeosporioides in vitro by the mechanism of competition, hyperparasites, and antibiosis.

There was an indication that Trichoderma spp. have an antibiosis mechanism in controlling plant diseases caused by Colletotrichum in chili. Therefore, it is necessary to conduct research on the utilization of secondary metabolites produced in culture medium of Trichoderma spp. to inhibit the growth of $C$. gloeosporioides that cause anthracnose in chili. The purpose of this study was to evaluate the antifungal activity of the culture filtrate of five isolates of Trichoderma spp. (T. harzianum, T. viride, $T$. koningii, Trichoderma PP2, Trichoderma PP3) against C. gloeosporoides causing anthracnose disease in chili

\section{MATERIALS AND METHODS}

The study was conducted in the Phytopathology Laboratory of the Agriculture Faculty, Andalas University, Padang from March to September 2018. The design was a Completely Randomized Design (CRD) consisting of six treatments and four replications. The treatments were culture filtrate of five Trichoderma isolates, namely: $T$. viride, T. harzianum, T. koningii, Trichoderma PP2, and Trichoderma PP3 isolates and negative control (without culture filtrate) ). Each treatment has four replications. Data were statistically analyzed using Analysis of Variance and Duncan's Multiple Range Test (DMRT) at the 5\% level.

\section{Cultivation of Trichoderma spp.}

Trichoderma spp.: T. viride, T.harzianum, T. koningii, Trichoderma PP2, and Trichoderma PP3 isolates with indication of having antibiosis activity were cultured on Potato Dextrose Agar (PDA) medium for seven days

\section{Cultivation of Trichoderma spp in the liquid medium}

Cultivation of Trichoderma in liquid medium was carried out in two techniques: 1) single culture technique of Trichoderma: Trichoderma was cultivated in a liquid medium of Potato Dextrose Broth, contains of $200 \mathrm{~g}$ potato, $20 \mathrm{~g}$ dextrose and $1000 \mathrm{~mL}$ distilled water and $\mathrm{pH}$ were adjusted 6.0. The medium was put as much as $100 \mathrm{ml}$ into Erlenmeyer tube $250 \mathrm{ml}$ and sterilized in an autoclave for 30 minutes at $15 \mathrm{psi}$ and $121^{\circ} \mathrm{C}$. The sterilized medium was placed in laminar airflow for the inoculation of Trichoderma spp. Inoculation was carried out by adding 10 $\mathrm{ml}$ conidial suspension of Trichoderma $\left(10^{6}\right.$ conidia $\left./ \mathrm{mL}\right)$ in to an Erlenmeyer tube containing $100 \mathrm{ml}$ of PDB medium (10\% of the total medium). Subsequently incubated for five days at room temperature and then incubation was continued in a rotary shaker at a speed of $180 \mathrm{rpm}$ for seven days. 2) dual culture technique of Trichoderma and C. gloeosporoides simultaneously. Cultivation was carried out in the Potato Dextrose Broth (PDB) as mention above. Inoculation was carried out by adding $10 \mathrm{ml}$ conidial suspension each of Trichoderma and C. gloeosporoides $\left(10^{6}\right.$ conidia/mL) into an Erlenmeyer tube containing 100 $\mathrm{ml}$ of PDB medium. Next incubated for five days at room temperature, incubation was continued on a rotary shaker at a speed of $180 \mathrm{rpm}$ for seven days. (Kumar et al. 2014).

\section{Culture filtrate of Trichoderma spp}

Liquid growth media as mention above was separated from biomass of Trichoderma spp for single culture and biomass of Trichoderma spp and C. gloeosporoides for dual culture techniques using Whatman filter paper. The filtrate was centrifuged at $4000 \mathrm{rpm}$ for 30 minutes, then filtered again using Whatman paper into another Erlenmeyer. The obtained filtrate was prepared by passing through Millipore filter membrane $0.2 \mu \mathrm{m}$

\section{Culture of Colletotrichum gloeosporioides}

The pathogenic fungus $C$. gloeosporioides was isolated from infected chili fruit with anthracnose symptoms characterized by dry brownish-black rot with sunken lesions in fruit skin. The isolation was carried out by the moist chamber method. First the surface sterilization is carried out on symptomatic fruit by washing with sterile aquadest, then the fruit is soaked in a plastic box containing Natrium hypoclorit $1 \%(\mathrm{NaOCl} 1 \%$ ) for tree minutes and then rinsed with sterile aquadest. The fruit is cut into 0.5 $\mathrm{cm}$ size by inserting symptomatic and healthy parts. Five pieces of fruit were placed in a plastic petri dish covered with moistened filter paper and incubated for 48 hours. The fungus that grows on the fruit was isolated in a petri dish containing a PDA medium, the fungal colony that has the characteristic of $C$. gloeosporoides is isolated again until its pure culture is obtained. Furthermore pure cultures are identified macroscopically and microscopically by referring to the literature (Alexopoulos et al. 1995; Agrios 2005).

\section{Inhibition test of culture filtrate against $C$. gloeosporoides}

One $\mathrm{mL}$ of Trichoderma culture filtrate from single or dual culture techniques was mixed evenly with $9 \mathrm{ml}$ of PDA medium at $40^{\circ} \mathrm{C}$ and poured onto Petri dishes. Cultures of $C$. gloeosporioides on PDA was cut using a core borer with a diameter of $0.5 \mathrm{~cm}$ and placed in the center of a Petri dish. Petri dish was incubated at room temperature until the culture in control covered the entire PDA surface.

\section{Parameters observed}

Growth inhibition of C. gloeosporioides colonies

Diameter and colony coverage of $C$. gloeosporoides colonies were observed by measuring the diameter of the fungal colonies using a ruler. Colony coverage was 
measured using millimeter plastic paper. observations were done every day until up to 12 days after inoculation of $C$. gloeosporoides.

\section{Evaluation of conidial germination and conidial density of C. gloeosporioides}

Conidial germination of $C$. gloeosporoides was determined by the method of Junianto and Sukamto (1995). PDA in the form of a plate with an area of about $1 \mathrm{~cm}^{2}$ and 1-2 mm thickness was placed on a sterile object-glass, then $10 \mu \mathrm{l}$ of conidial suspension containing $10^{6}$ conidia $/ \mathrm{mL}$ was transferred on PDA medium. The object-glass was placed in sterile Petri dishes containing a moistened filter paper and incubated at room temperature for 24 hours. Observation was using a light microscope with a magnification of 400 times. Germination was observed by counting the number of conidia that germinated divided by the total number of conidia observed.

Conidial density of $C$. gloeosporoides was determined by preparing; $C$. gloeosporoides culture on PDA medium that has been added with filtrate of Trichoderma spp. that incubated for 12 days (the control dish was full colony coverage). Furthermore, the conidia were crushed using a small brush and stirred evenly with distilled water. The suspension was inserted into the test tube, and a dilution of $10^{-1}$ was made. The number of $C$. gloeosporioides conidia which cultivated on PDA incorporated with culture filtrate of Trichoderma spp. was calculated using a hemocytometer. The observation was carried out using a light microscope with a magnification of 400x.

\section{RESULTS AND DISCUSSION}

The effect of culture filtrate of Trichoderma spp. to the growth of $C$. gloeosporioides: Single culture technique

Culture filtrate of Trichoderma spp. incorporated with PDA affected the growth of C. gloeosporioides significantly over control (Table 1). Culture filtrates of Trichoderma spp. contain secondary metabolites derived from Trichoderma spp were able to suppress the growth of C. gloeosporioides in various degree. The highest growth suppression was recorded in Trichoderma PP2 with the effectivity $67.80 \%$, and $T$. koningi had the effectivity 25.89 $\%$ in suppressing the colony coverage $r$. The highest colony growth was recorded in negative control without culture filtrate of Trichoderma spp.

The high ability of culture filtrates of $T$. koningii and Trichoderma PP2 in inhibiting the growth of $C$. gloeosporioides was due to the secondary metabolites contain in culture filtrate that has antifungal activity. Vinale et al. (2006) reported that the secondary metabolites of $T$. harzianum strain T22 and T39 have antifungal activity so that they can inhibit the growth of pathogenic fungi like Leptosphaera muculans, Phytophthora cinnamomi, and Botrytis cinerea. In this study, T. koningii and Trichoderma PP2 have better ability in inhibiting the growth of $C$. gloeosporioides than T. harzianum. It is due to different species or isolates in the same species of Trichoderma produce different types of secondary metabolites (Wu et al. 2017) so that they have different abilities in inhibiting the growth of pathogenic fungi.

\section{Conidial germination and conidial density of $\mathrm{C}$. \\ gloeosporioides}

Culture filtrate of Trichoderma spp. showed a significantly different effect on the conidial density and germination of $C$. gloeosporioides conidia (Table 2). Trichoderma spp. produce secondary metabolites that able to suppress the formation of $C$. gloeosporioides conidia with the conidial density of $1.3-1.65 \times 10^{8} / \mathrm{mL}$ and the germination of conidia was in the range $21.33-32.37 \%$ which were much lower than the control treatment $(4.60$ $\left.\mathrm{x} 10^{8} / \mathrm{mL}\right)$.

In general, culture filtrate of Trichoderma spp. reduces the germination of $C$. gloeosporoides conidia. The lowest germination $(21.33 \%)$ was in the treatment of culture filtrate from $T$. harzianum with the effectiveness of $72.21 \%$. The results of this study showed that reduction of germination caused by culture filtrate of Trichoderma spp. was varied. Vinale et al. (2014) reported that viridin, a secondary metabolite produced by $T$. koningii and $T$. virens was able to inhibit conidial germination of the fungi Botrytis alii, $C$. line, and $F$. cauruleum. Differences in ability to reduce germination rate by different Trichoderma isolates may be caused by different secondary metabolites that were produced so that the ability to inhibit the conidial germination of pathogenic fungi was also different.

Table 1. Effect of culture filtrates of Trichoderma spp. on the growth $C$. gloeosporioides colonies in single culture

\begin{tabular}{lllll}
\hline \multicolumn{1}{c}{ Treatment } & $\begin{array}{l}\text { Colony } \\
\text { coverage } \\
\left(\mathbf{m m}^{2}\right)\end{array}$ & $\begin{array}{c}\text { Effecti- } \\
\text { veness } \\
(\boldsymbol{\%})\end{array}$ & $\begin{array}{l}\text { Diameter } \\
\text { of colony } \\
(\mathbf{c m})\end{array}$ & $\begin{array}{c}\text { Effecti- } \\
\text { veness } \\
(\boldsymbol{\%})\end{array}$ \\
\hline Control & $4792.30^{\mathrm{a}}$ & 0 & $8.87^{\mathrm{a}}$ & 0 \\
T. viride & $4514.50^{\mathrm{ab}}$ & 5.79 & $8.00^{\mathrm{b}}$ & 9.8 \\
Trichoderma PP3 & $4492.30^{\mathrm{ab}}$ & 6.26 & $7.37^{\mathrm{c}}$ & 16.91 \\
T. harzianum & $4230.30^{\mathrm{b}}$ & 11.72 & $7.42^{\mathrm{c}}$ & 16.34 \\
T. koningi & $3551.30^{\mathrm{c}}$ & 25.89 & $6.60^{\mathrm{d}}$ & 25.59 \\
Trichoderma $\mathrm{PP} 2$ & $1543.00^{\mathrm{d}}$ & 67.80 & $7.85^{\mathrm{b}}$ & 11.49 \\
& $\mathrm{CV}=8.30 \%$ & $\mathrm{CV}=9.42 \%$ \\
\hline
\end{tabular}

Note: Mean values having the same uppercase letter in the column do not significantly different at the $5 \%$ level by DMRT.

Table 2. Conidial density and germination of C.gloeosporoides treated with culture filtrate of Trichoderma spp. in single culture

\begin{tabular}{|c|c|c|c|c|}
\hline Treatment & $\begin{array}{c}\text { Conidial } \\
\text { density } \\
\left(\times 10^{8} / \mathbf{m L}\right. \\
\text { suspension) }\end{array}$ & $\begin{array}{c}\text { Effecti- } \\
\text { veness } \\
(\%)\end{array}$ & $\begin{array}{l}\text { Germi- } \\
\text { nation } \\
\text { of } \\
\text { conidia } \\
(\%)\end{array}$ & $\begin{array}{c}\text { Effecti- } \\
\text { veness } \\
(\%)\end{array}$ \\
\hline Control & $4.60 \mathrm{a}$ & 0 & $76.76 a$ & 0 \\
\hline T. viride & $1.65 b$ & 64.13 & $32.37 b$ & 57.82 \\
\hline T. harzianum & $1.60 \mathrm{~b}$ & 65.21 & $21.33 c$ & 72.21 \\
\hline T. koningi & $1.50 \mathrm{bc}$ & 67.39 & $21.94 \mathrm{c}$ & 71.41 \\
\hline Trichoderma.PP2 & $1.50 \mathrm{bc}$ & 67.39 & $31.27 \mathrm{~b}$ & 59.26 \\
\hline Trichoderma.PP3 & $1.30 \mathrm{c}$ & 71.73 & $23.74 \mathrm{c}$ & 69.07 \\
\hline & $\mathrm{CV}=8.59$ & \multicolumn{3}{|c|}{$\mathrm{CV}=12.32$} \\
\hline
\end{tabular}

Note: The numbers followed by the same uppercase letter on the same column are not significantly different at the $5 \%$ level by DMRT 
Growth rate (colony diameter) of C. gloeosporioides treated with culture filtrate of Trichoderma spp. was lower than control. The lowest growth rate was in the treatment of culture filtrate produced by T. koningii (Figure 1).

Colony growth of $C$. gloeosporioides on Potato Dextrose Agar medium incorporated with culture filtrate of Trichoderma spp. was dominated by mycelium formation while conidia formation was inhibited compared to the control (Figure 2).

\section{The effect of culture filtrate of Trichoderma spp. to the} growth of $\boldsymbol{C}$. gloeosporioides: Dual Culture Technique Growth inhibition of C. gloeosporioides

The treatment of culture filtrate incorporation of Trichoderma spp. produced by dual culture technique showed a significantly different effect among treatments to the colony coverage and diameter of $C$. gloeosporioides colonies (Table 3). Trichoderma spp. produced secondary metabolites that could suppress the growth of $C$. gloeosporioides. Culture filtrate of Trichoderma $\mathrm{PP} 2$ results in complete growth inhibition of $C$. gloeosporioides, while culture filtrate of $T$. harzianum caused growth inhibition of C. gloeosporioides with colony coverage was $1568.80 \mathrm{~mm}^{2}$ (effectiveness $39.45 \%$ ), and diameter of colony was $5.37 \mathrm{~cm}$. Colony coverage and diameter of colony in negative control were $4792.30 \mathrm{~mm}^{2}$ and $8.87 \mathrm{~cm}$ respectively.

Dual culture technique results in higher growth suppression of pathogenic fungi because they grew simultaneously on the same media at the same time so that Trichoderma during its growth and propagation will produce secondary metabolite compounds maximally for competing against $C$. gloeosporoides. Kumar et al. (2014) reported that secondary metabolites of $T$. harzianum (Th Ahad) and $T$. viridae (O1PP) produced in liquid medium simultaneously with pathogenic fungi were more effective to suppress the growth of $F$. oxysporum f.sp. lenti, Rhizoctonia solani, and Sclerotinia rolfsii. The higher of the secondary metabolite concentration, the more inhibition of pathogenic growth.

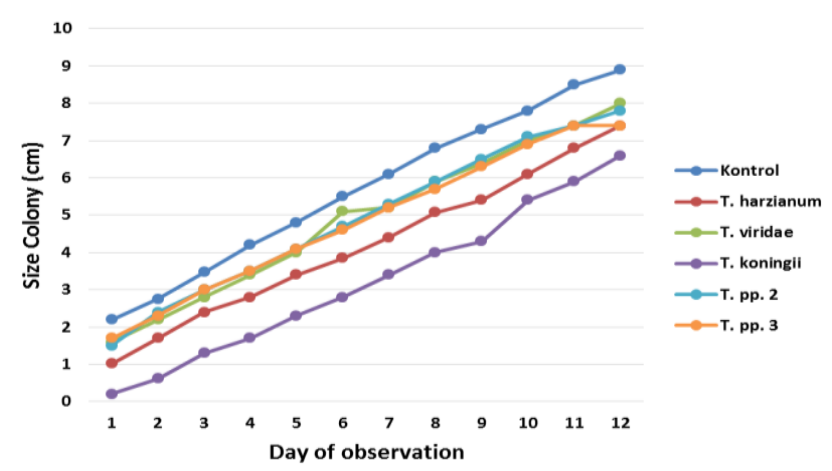

Figure 1. Growth rate (colony diameter) of $C$. gloeosporioides treated with culture filtrate of Trichoderma spp produced by Single Culture Technique

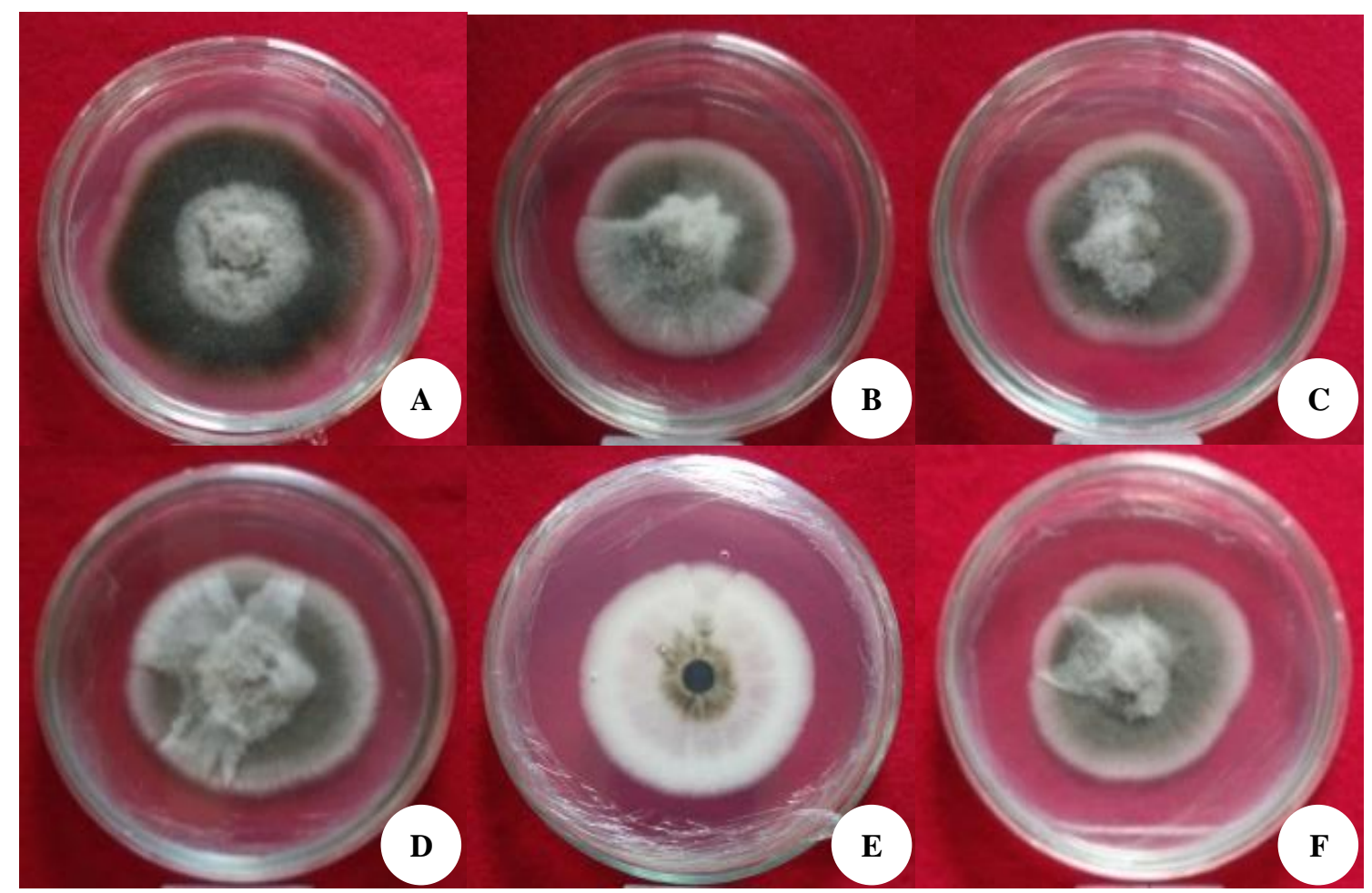

Figure 2. Growth of C. gloeosporioides treated with culture filtrate of Trichoderma spp at 10 days after inoculation. A. Control, B. Trichoderma PP3, C. Trichoderma harzianum, D. Trichoderma koningii, E. Trichoderma PP2, F. Trichoderma viride 
The culture medium of Trichoderma PP2 was able to inhibit the growth of $C$. gloeosporioides completely. It indicated that Trichoderma PP2 was superior to other isolates in producing secondary metabolites as antifungal. According to Harman et al. (2004) Trichoderma spp. can produce hydrolytic enzymes that can destroy pathogenic cell walls such as chitinase, $\beta 1.3$ glucanases, and protease.

The culture medium of $T$. koningii and PP3 result in the growth of $C$. gloeosporioides colonies was slower than culture medium of $T$. harzianum and $T$. koningii treatment (Figure 3).

Table 3. Effect of culture filtrates of Trichoderma spp. produced by dual culture method on the growth $C$. gloeosporioides colonies

\begin{tabular}{lcccc}
\hline \multicolumn{1}{c}{ Treatment } & $\begin{array}{c}\text { Colony } \\
\text { coverage } \\
\left(\mathbf{m m}^{2}\right)\end{array}$ & $\begin{array}{c}\text { Effecti- } \\
\text { veness } \\
(\boldsymbol{\%})\end{array}$ & $\begin{array}{c}\text { Diameter } \\
\text { of colony } \\
(\mathbf{c m})\end{array}$ & $\begin{array}{c}\text { Effecti- } \\
\text { veness } \\
(\%)\end{array}$ \\
\hline Control & $4792.30 \mathrm{a}$ & 0 & $8.87 \mathrm{a}$ & 0 \\
T.viride $+\mathrm{Cg}$ & $4470.50 \mathrm{a}$ & 6.71 & $7.85 \mathrm{~b}$ & 11.49 \\
Trichoderma PP3 $+\mathrm{Cg}$ & $2673.80 \mathrm{~b}$ & 44.20 & $5.40 \mathrm{c}$ & 39.12 \\
T.koningii $+\mathrm{Cg}$ & $2173.80 \mathrm{~b}$ & 54.63 & $5.95 \mathrm{c}$ & 32.91 \\
T.harzianum $+\mathrm{Cg}$ & $1568.80 \mathrm{c}$ & 67.26 & $5.37 \mathrm{c}$ & 39.45 \\
Trichoderma PP2+ Cg. & $0.00 \mathrm{~d}$ & 100 & $0.00 \mathrm{~d}$ & 100 \\
& $\mathrm{CV}=9.56$ & & $\mathrm{CV}=8.23$ \\
\hline
\end{tabular}

Note: Mean values having the same uppercase letter in the column do not significantly different at the $5 \%$ level by DMRT. Cg: $C$. gloeosporioides

Table 4. Conidial density and germination of $C$. gloeosporoides treated with culture filtrate of Trichoderma spp. in Dual Culture Technique

\begin{tabular}{|c|c|c|c|c|}
\hline Treatment & $\begin{array}{c}\text { Conidial } \\
\text { density } \\
\left(\times 10^{8} / \mathrm{mL}\right. \\
\text { supension })\end{array}$ & $\begin{array}{c}\text { Effecti- } \\
\text { veness } \\
(\%)\end{array}$ & $\begin{array}{c}\text { Germi- } \\
\text { nation of } \\
\text { conidia } \\
(\%)\end{array}$ & $\begin{array}{c}\text { Effecti- } \\
\text { veness } \\
(\%)\end{array}$ \\
\hline Control & $40.60 \mathrm{a}$ & 0 & $76.76 \mathrm{a}$ & 0 \\
\hline T. harzinum $+\mathrm{Cg}$ & $19.00 \mathrm{~b}$ & 53.20 & $34.47 \mathrm{~b}$ & 55.09 \\
\hline T. koningii $+\mathrm{Cg}$ & $16.50 \mathrm{~b}$ & 59.35 & $33.70 \mathrm{~b}$ & 56.09 \\
\hline T.viride $+C g$ & $16.00 \mathrm{~b}$ & 60.59 & $36.19 b$ & 52.85 \\
\hline Trichoderma $. \mathrm{PP} 3+\mathrm{Cg}$ & $8.50 \mathrm{c}$ & 79.06 & $32.40 \mathrm{~b}$ & 57.79 \\
\hline Trichoderma $. \mathrm{PP} 2+\mathrm{Cg}$ & $\begin{array}{c}0 \mathrm{c} \\
\mathrm{CV}=11.52\end{array}$ & 100 & $\begin{array}{c}0 \mathrm{c} \\
\mathrm{CV}=16.3\end{array}$ & 100 \\
\hline
\end{tabular}

Note: The numbers followed by the same uppercase letter on the same column are not significantly different at the $5 \%$ level by DMRT. Cg: C. gloeosporioides

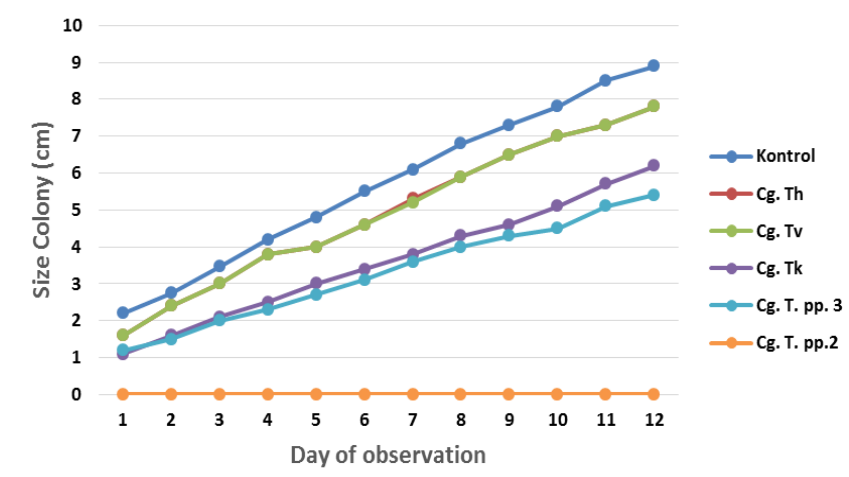

Figure 3. Growth rate (colony diameter) of C. gloeosporioides treated with culture filtrate s of Trichoderma spp. by dual culture
Conidial germination and conidial density of $\mathrm{C}$.

gloeosporioides

The treatment of Trichoderma spp in dual culture showed different effects significantly to the conidial germination and conidial density of C. gloeosporioides (Table 4). In general, culture medium of Trichoderma spp. was able to suppress the growth of $C$. gloeosporioides in various degree. Conidial density in Trichoderma spp. treatment was varied from 8.50 to $19.00 \times 10^{8} / \mathrm{mL}$, and conidial germination varied from 32.4 to $34.47 \%$. Treatment with culture filtrate of Trichoderma PP2 causes complete inhibition of conidial germination and conidial density, while conidial density and conidial germination in negative control was $40.60 \times 10^{8} / \mathrm{mL}$ and $76.76 \%$ respectively (Table 4).

Secondary metabolites produced in culture medium by Trichoderma PP2, T. koningii and Trichoderma PP3. were superior to suppress the formation of $C$. gloeosporioides conidia. It is related to the ability to suppress the growth of C. gloeosporioides (Figure 3) so that the conidial density and conidial germination were also inhibited. Meena et al. (2017) reported that $T$. harzianum and $T$. viride produce volatile and non-volatile compounds of secondary metabolites that effectively inhibit the growth and spore production of Fusarium spp. and Alternaria alternata.

Secondary metabolites of Trichoderma PP2 from dual culture inhibit the growth of $C$. gloeosporioides completely, so neither mycelium nor conidia were not formed. It indicated that the secondary metabolites of Trichoderma PP2 were very potential as antifungal. According to Daniel et al. (2014), secondary metabolites of T. asperellum T2-31 extract inhibit sporulation and germination of $F$. oxysporum conidia. The result of this study can be concluded that culture medium or culture filtrate from Trichoderma spp produced by single and dual culture used in this study can inhibit the growth of $C$. gloeosporoides. Secondary metabolites of Trichoderma PP2 and T. koningii were the best in inhibiting the growth, formation, and germination of $C$. gloeosporoides conidia.

\section{ACKNOWLEDGEMENTS}

The authors thank the Institute of Research and Community Service at Andalas University, Padang, Indonesia for funding this research, through the research contract of the Professor's Acceleration Research Cluster Scheme Number: 50/UN.16.17/ PP.PGBGB/LPPM/2018

\section{REFERENCES}

Agrios GN. 2005. Plant Pathology. $5^{\text {th }}$ ed. Elsevier Academic Press Inc., New York

Alexopoulos CJ, Mims CW, Blackwell M. 1996. Introductory Mycology. Fourth Edition. John Wiley and Sons, Inc. New York

Daniel FCH, Wilfredo FF, Fransisco RC, Gabriel MG, Epitanio ADC. 2014. Antibiosis In vitro of Trichoderma strains metabolic extract on mycelial growth and reproductive capacity of Fusarium oxysporum isolated from Pepper plants (Capsicum annuиm L). Br Biotechnol J 4 (4): 387-399. 
Diao YZ, Zhang C, Liu F, Wang WZ, Liu L, Chai L, Liu XL. 2017. Colletotrichum species causing Anthracnose disease of Chili in China. Personia 38: 20-37.

Druzhinina IS., Kopchinsky AG, Kubicek CP. 2006. The first 100 Trichoderma species characterized by molecular data. Mycoscience 47 (2): 55-64.

Dubey SC, Tripathi A, Durejo P, Grover A. 2011. Characterization of Secondary metabolite and enzyme produced by Trichoderma species and their efficacy against plant pathogenic fungi. Indian J Agric Sci 81 (5):455-461.

Harman GE, Howell CR, Viterbo A, Chet I, Lorito M. 2004. Trichoderma species-opportunistic, avirulent plant symbionts. Nature Rev Microbiol 2: 43-56.

Howell CR. 2003. Mechanisms employed by Trichoderma species in the biological control of plant diseases: the history and evolution of current concepts. Plant Dis 87: 4-10.

Junianto YD, Sukamto S. 1995. Effect of temperature and humidity relative to germination, growth and sporulation of several isolates of Beauveria bassiana. Pelita Perkebunan 11 (2).64-75.

Kumar V, Shahid M, Srivastava M, Pandey S, Singh A, Sharma A. 2014 Role of secondary metabolite produced by commercial Trichoderma Species and their effect against soil-borne pathogens. Biosens J 1 (3): 2-5.

Leelavathy MS, Vani L, Reena P. 2014. Antimicrobial activity of Trichoderma harzianum against bacteria and fungi. Intl J Curr Microbiol Appl Sci 3 (1): 96-103.

Meena M, Swapnil P, Zehra A, Dubey MH, Upadhyay RS. 2017. Antagonistic assessment of Trichoderma spp. by producing volatile and non-volatile compounds against different fungal pathogens. J Arch Phytopathol Plant Protect 50: 13-14.

Mutawila C, Vinale F, Halleen F, Lorito M, Mostert L. 2016. Isolation, production and in vitro effects of the major secondary metabolite produced by Trichoderma species used for the control of grapevine trunk diseases. Plant Pathol 65: 104-113.
Nurbailis, Mardinus, Nasril, N. Dharma, A. 2006. Screening of Trichoderma Isolates from rhizosphere of banana plants in West Sumatra to control Fusarium wilt disease. Akta Agrosia Journal 9 (1): 49-55. [Indonesian]

Nurbailis, Martinius, Azniza V. 2014. Fungi diversity in chilli rhizosphere organic and conventional systems and their potential as biological control agents of Colletotrichum gloeosporoides. J Hpt Tropika 14 (1): 16-24. [Indonesian]

Robert PD, Pernezny KL, Kucharek TA. 2015. Anthracnose on Pepper in Florida.UF/IFAS Extension University of California, Los Angeles.

Roberts PD, Pernezny KL, Kucharek TA. 2008. Anthracnose caused by Colletotrichum sp on Pepper. http://edis.ifas.ufl.edu/PP104.

Samuel GJ. 1996. Trichoderma: a review of biology and systematics of the genus. Mycol.Res 100 (8): 923-935

Sharma M, Kulshrestha S. 2015. Colletotrichum gloeosporoides: An anthracnose causing pathogen of fruit and vegetable. Biosci Biotechnol Res Asia 12 (2): 1-15.

Vinale F, Marra R, Scala F, Ghisalberti EL, Lorito M, Sivasithamparam K. 2006. Major secondary metabolites produced by two commercial Trichoderma strains active against different phytopathogens. Lett App Microbiol 43: 143-8.

Vinale F, Sivasithamparam K, Ghisalberti EL, Woo SL, Nigro M, Marra R, Lombardi N, Pascale A, Roucco M, Lanzuise S, Manganiello G, Lorito M. 2014. Trichoderma secondary metabolites active on plants and fungal pathogens. Open Mycol J 8 (Suppl-1, M5): 127-139.

Vinale FK, Sivasithamparam LE, Ghisalberti R. Marra LS, Lorito M. 2008. Trichoderma-plant-pathogen interactions. Soil Biol Biochem 40: $1-10$.

Woo SL, Scala F, Ruocco M, Lorito M. 2006. The molecular biology of the interactions between Trichoderma spp., phytopathogenic fungi and plants. Phytopathology 96: 181-185.

Wu Q, Sun R, Ni M, Yu J, Li Y, Yu C, Dou K, Ren J, Chen J. 2017. Identification of a novel fungus, Trichoderma asperellum GDFS1009, and comprehensive evaluation of its biocontrol efficacy. PloS ONE 12(6): e0179957. DOI: 10.1371/journal.pone.0179957 